\title{
Biotransformation of Indigo Pigment by Indigenously Isolated Pseudomonas sp. HAV-1 and Assessment of Its Antioxidant Property
}

\author{
Aditi Dua, ${ }^{1}$ Kishor Chauhan, ${ }^{2}$ and Hilor Pathak ${ }^{1}$ \\ ${ }^{1}$ Department of Microbiology, P. D. Patel Institute of Applied Sciences, Charotar University of Science \& Technology, \\ Changa, Gujarat 388 421, India \\ ${ }^{2}$ Department of Biotechnology, Ashok \& Rita Patel Institute of Integrated Studies and Research in Biotechnology and \\ Allied Sciences (ARIBAS), Sardar Patel University, New Vallabh Vidyanagar, Gujarat 388 121, India
}

Correspondence should be addressed to Hilor Pathak; hilorpathak.mi@charusat.ac.in

Received 13 August 2014; Revised 8 October 2014; Accepted 22 October 2014; Published 17 November 2014

Academic Editor: Yau Hung Chen

Copyright (C) 2014 Aditi Dua et al. This is an open access article distributed under the Creative Commons Attribution License, which permits unrestricted use, distribution, and reproduction in any medium, provided the original work is properly cited.

Chemical synthesis of indigo poses harsh environmental hazards and adverse human health effects. This necessitates an environment-friendly and producer-friendly approach for indigo production. The present study was thus significant as it reports an indigenously isolated potential indigo pigment producing culture identified as Pseudomonas sp. HAV-1 with noteworthy antioxidant property. The bioindigo pigment was characterized using various analytical techniques. The pigment production was enhanced from $412 \mu \mathrm{g} \mathrm{mL}^{-1}$ to $700 \mu \mathrm{g} \mathrm{mL} \mathrm{m}^{-1}$ by optimizing the growth parameters. Furthermore, the antioxidant property of indigo pigment is hitherto unexplored. This property can significantly append to its therapeutic potential. The bioindigo pigment produced by Pseudomonas sp. HAV-1 depicted $2.2 \mu \mathrm{M}$ ascorbic acid equivalent antioxidant property. More to the point, the present work addresses a footstep towards green production of indigo.

\section{Introduction}

Indigoid pigments, a group of commodity chemicals, were anciently extracted from plants of Indigofera sp. Indigo (C. I. 73,000), a type of indigoid pigment, is one of the world's largest-produced dyes and has persistent applications in the textile industry [1]. However, the chemical synthesis of indigo not only imposed health hazards to workers but also led to severe environmental pollution due to the use of toxic materials like aniline, nitrobenzene, and metal salts $[2,3]$. Since the responsiveness and concern towards protection of the environment is gaining momentum, interest lies in identifying eco-friendly methods for the indigo synthesis. As a result, microbial synthesis of indigoid pigments is commendable over chemical synthesis [4].

Most of the aromatic hydrocarbon-degrading bacteria represent the ability to synthesize indigo dye [4-7]. Therefore, such processes render dual advantage of removal of the recalcitrant aromatic hydrocarbons from the environment as well as bioindigo production. Several microbial processes for indigo synthesis have been reported, but the main apprehension is the lower productivity when compared to the chemical processes [8]. Hence, interest lies in isolation of microbes that can produce indigo at a substantial rate. Once potential indigo producing microorganisms have been identified, the rate of indigo synthesis can be augmented employing well designed optimization strategy. The present work employed optimization studies based on response surface method (RSM) theory, which studies the influence of identified parameters and their individual and interactive effects, by performing a series of planned experiments and analyzing the response statistically. Furthermore, indigoid pigments have been reported to possess antileukemic, hemostatic, antipyretic, anti-inflammatory, and sedative properties [912]. These are aromatic compounds that portray tremendous therapeutic potential in a number of diseases which includes Alzheimer's disease, certain forms of cancer, and delayed hypersensitivity [4]. The antioxidant property of indigo 
from plant source is scarcely reported [13] and reports are lacking on evaluation of antioxidant property of bacterial derived indigo. This property can considerably augment its therapeutic prospective.

With this background, the present study was aimed at isolation of indigo producing microorganisms with higher yield. Optimization study based on response surface method (RSM) was employed, which studies the influence of identified parameters along with their interactive effects, by performing a series of planned experiments and analyzing the response statistically. Antioxidant property of the bioindigo was explored to enhance its therapeutic potential.

\section{Materials and Methods}

2.1. Sample Collection, Enrichment, and Isolation of Indigo Producing Organisms. Soil samples were collected from oil contaminated sites of Vadodara, India, and were employed for isolation of naphthalene degrading organisms by enrichment technique using Bushnell Haas Broth (BHB) spiked with naphthalene $\left(100 \mathrm{mg} \mathrm{L}^{-1}\right)$ as a sole carbon source. The medium was inoculated with soil sample $(10 \% \mathrm{w} / \mathrm{v})$ and incubated under shaking condition $\left(150 \mathrm{rpm}\right.$ at $\left.30^{\circ} \mathrm{C}\right)$. Repetitive transfers were carried out into fresh naphthalene spiked medium until consistent visual growth and naphthalene degradation were observed. This enrichment culture was plated on Bushnell Haas agar containing naphthalene $\left(100 \mathrm{mg} \mathrm{L}^{-1}\right)$ and incubated at $30^{\circ} \mathrm{C}$ for $24 \mathrm{~h}$. The isolates obtained upon enrichment were subjected to indigo biotransformation using indole ( $3 \mathrm{mM})$ as substrate. The isolate HAV1 showed highest indigo formation was selected for further studies (refer to Figure 1 in Supplementary Material available online at http://dx.doi.org/10.1155/2014/109249). The isolate $\mathrm{HAV}-1$ was routinely grown at $30^{\circ} \mathrm{C}$ in Bushnell Haas broth (BHB) with naphthalene $\left(100 \mathrm{mg} \mathrm{L}^{-1}\right)$ and incubated under shaking conditions for $24 \mathrm{~h}$. This was used as inoculum in the present study unless specified.

\subsection{Identification of Indigo Producing Culture HAV-1. The} isolate HAV-1 was subjected to genomic DNA extraction by phenol-chloroform method as described by Ausubel et al., 1997 [14]. Universal bacterial 16S rRNA gene primers corresponding to Escherichia coli position 8f and 1492r were used for polymerase chain reaction (PCR) amplification of the $16 \mathrm{~S}$ rRNA gene [15]. Purified PCR products were sequenced using internal overlapping primers [15]. Sequence was initially analyzed at NCBI server (http://www.ncbi.nlm.nih.gov/) using BLAST (blastn) tool and corresponding sequences were downloaded. Similarly matrix was prepared using Dnadist program in PHYLIP analysis package [16] using Jukes Cantor corrections. Phylogenetic tree was constructed by neighbourjoining method using the MEGA package.

2.3. Biosynthesis, Extraction, and Characterization of Blue Pigment. Isolate HAV-1 was inoculated (10\%) in BHB spiked with naphthalene $(100 \mathrm{mg} / \mathrm{L})$ and incubated for $24 \mathrm{~h}$ at $30^{\circ} \mathrm{C}$ under shaking conditions. The broth was filtered using Whatman filter paper 1 to remove residual naphthalene and indole was added to the filtrate at a final concentration of $3 \mathrm{mM}$. The blue pigment from the whole culture broth was extracted using equal volume of chloroform and it was evaporated to obtain dried powder. The dried pigment was dissolved in $10 \mathrm{~mL}$ of HPLC grade chloroform. The pigment was analyzed by thin-layer chromatography (TLC) and Fourier Transform Infrared (FTIR) spectroscopy (NICOLET 6700, Thermo Scientific, USA). TLC and FTIR were performed as described earlier [4]. The pigment was also scanned in the range of 200$800 \mathrm{~nm}$ using double beam UV-Visible spectrophotometer (Systronics 2203, India). A similar characterization study was performed with commercial indigo for comparison purpose.

2.4. Induction Profile for Indigo Formation. In order to study the induction profile for indigo formation, each culture flask was harvested at a regular time interval of 4 hours. The culture broth of harvested flask was filtered using Whatman filter paper and the filtrate containing cells was used to determine indigo formation by method of O'Connor and Hartmans (1998) [17]. The absorbance of the indigo pigment was determined at $610 \mathrm{~nm}$. Flask containing BHB spiked with (100 $\mathrm{mg} \mathrm{L}^{-1}$ ) naphthalene along with $3 \mathrm{mM}$ indole without isolate HAV-1 was used as control.

2.5. Effect of Inoculum Size and Indole Concentration on Indigo Production Using Response Surface Method. Response surface method was used to evaluate the individual as well as the combined effect of indole concentration and inoculum size on indigo formation using the central composite design (CCD). The "Design-Expert" version 8.0, State-Ease Inc., Minneapolis, USA, was used for experimental design, regression, and graphical analysis of the data obtained [14, 18]. Indole concentration and inoculum size were studied at five different levels (SM Table 1). A set of 13 experiments was performed (SM Table 2). The minimum and maximum ranges of variables were used and the full experiment design with respect to their values was generated. The data obtained from RSM on pigment production was subjected to the analysis of variance (ANOVA) and the results of RSM were used to fit a second order polynomial equation:

$$
Y=\beta_{0}+\beta_{1} A+\beta_{2} B+\beta_{1} \beta_{2} A B+\beta_{1} \beta_{1} A^{2}+\beta_{2} \beta_{2} B^{2},
$$

where $Y$ is response variable (dependent variable), $\beta_{0}$ is intercept (constant), $\beta_{1}, \beta_{2}$ are linear coefficients, $\beta_{1} \beta_{2}$ is interaction coefficient, $\beta_{1} \beta_{1}, \beta_{2} \beta_{2}$ are squared coefficients, and $A, B, A B, A^{2}$, and $B^{2}$ are level of independent variables.

2.6. Evaluation of Antioxidant Activity of Biosynthesized Indigo Pigment. The antioxidant activity of the extracted indigo pigment as well as the commercial indigo pigment was determined employing the FRAP assay [19] and the ABTS assay [20] to obtain ferric reducing as well as total antioxidant power of the pigment. The antioxidant power was estimated in terms of ascorbic acid equivalents. 


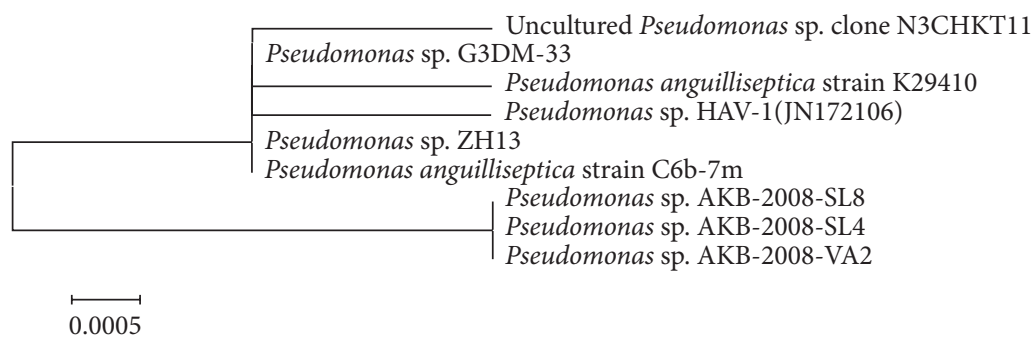

FiguRE 1: Phylogenetic tree derived from 16S rRNA gene sequence of isolate HAV-1. Sequences of closest phylogenetic neighbors obtained by NCBI BLAST $(n)$ analysis; numbers in the parenthesis indicate accession numbers of corresponding sequences. The NJ-tree was constructed using neighbor joining algorithm with Kimura 2 parameter distances in MEGA 5.0 software.

TABLE 1: ANOVA for response surface quadratic model.

\begin{tabular}{|c|c|c|c|c|c|c|}
\hline Source & Sum of squares & $\mathrm{df}$ & Mean square & $F$ value & $\begin{array}{c}P \text { value } \\
\text { Prob }>F\end{array}$ & \\
\hline Model & 0.178603 & 3 & 0.059534 & 10.7657 & 0.0219 & Significant \\
\hline$A:$ inoculum size & 0.000182 & 1 & 0.000182 & 0.00634 & 0.9388 & \\
\hline$B$ : indole concentration & 0.033406 & 1 & 0.033406 & 1.164996 & 0.3162 & \\
\hline$A B$ & 0.000156 & 1 & 0.000156 & 0.005449 & 0.9432 & \\
\hline$A^{2}$ & 0.000636 & 1 & 0.000636 & 0.022184 & 0.8858 & \\
\hline$B^{2}$ & 0.157436 & 1 & 0.157436 & 5.490418 & 0.0516 & \\
\hline Residual & 0.200723 & 7 & 0.028675 & & & \\
\hline Lack of fit & 0.197208 & 5 & 0.039442 & 1.375483 & 0.3378 & Not significant \\
\hline
\end{tabular}

$R^{2}: 0.93$, Adj. $R^{2}: 0.85$, Pred. $R^{2}: 0.97$, Adqt. Prec.: 15.

\section{Results and Discussion}

3.1. Isolation and Screening of Indigo Producing Bacteria. Three naphthalene degrading enrichment cultures designated as HAV-1, HAV-2, and HAV-3 were obtained after enrichment of hydrocarbon contaminated sediment samples. These isolates were found to be capable of naphthalene degradation (observed visually for the disappearance of naphthalene flakes from BHB broth). Among the three enrichment cultures, HAV-1 depicted the ability to utilize naphthalene at a faster rate (refer to Figure 1 in Supplementary Mterial). Hence HAV-1 was selected for further studies.

3.2. $16 S$ rRNA-Based Culture Identification. Isolate HAV-1 was identified using 16S rRNA gene based approach. The DNA sequencing and BLAST analysis of $16 \mathrm{~S}$ rRNA gene sequence of the isolate HAV-1 showed maximum sequence homology (99\%) with the complete sequence of Pseudomonas sp. 16S rRNA gene. Phylogenetic analysis indicates that the newly isolated strain HAV-1 is affiliated to Pseudomonas species and hence in the present study it is referred to as Pseudomonas sp. HAV-1. The phylogeny cluster of HAV-1 along with related Pseudomonas species (a Gamma-proteobacteria) is depicted in Figure 1. The gene sequence was submitted to Genbank with accession number JN172106.

3.3. Characterization of Blue Pigment. The blue pigment produced by the isolate Pseudomonas sp. HAV-1 was characterized by TLC and FTIR. Indigo produced portrayed only one band when analyzed by TLC. The $R_{f}$ value of indigo pigment matched exactly that of the commercial indigo pigment (Figure 2(a)). This implies that the blue pigment produced by isolate Pseudomonas sp. HAV-1 is indigo pigment. This was supported by the UV-Visible spectrum of the extracted blue pigment which was identical to that of the commercial indigo pigment (Figure 2(b)). The infrared spectrum accounted for the specificity of any compound and can be used as its "fingerprint" for identification purposes. Figure 2(c) depicts the infrared spectrum of the extracted blue pigment. The FT-IR spectrum of the purified blue pigment shows a peak at $3,398 \mathrm{~cm}^{-1}$ that is attributed to the $\mathrm{N}-\mathrm{H}$ stretching in secondary amines. A peak at $1,617 \mathrm{~cm}^{-1}$ may be attributed to $\mathrm{C}=\mathrm{O}$ stretching coupled with $\mathrm{C}=\mathrm{C}$ stretching. Further, weak bands in the range of $1,350-1,000 \mathrm{~cm}^{-1}$ have contributions from $\mathrm{C}-\mathrm{N}$ stretching of the amine group. The peak around $735-770 \mathrm{~cm}^{-1}$ may be assigned to $\mathrm{C}-\mathrm{H}$ out of the plane bending in aromatic group. Thus, the IR spectrum of the microbial synthesized compound supports the identification of blue pigment as indigo dye.

3.4. Time Course Study for Indigo Formation by HAV-1. Indigo formation increased linearly during initial $20 \mathrm{~h}$ of the growth and reached maximum $412 \mu \mathrm{g} \mathrm{mL}^{-1}$ and decreased thereafter (Figure 3). No indigo formation was observed in the control flask suggesting the role of Pseudomonas sp. HAV-1 in indigo biosynthesis. 


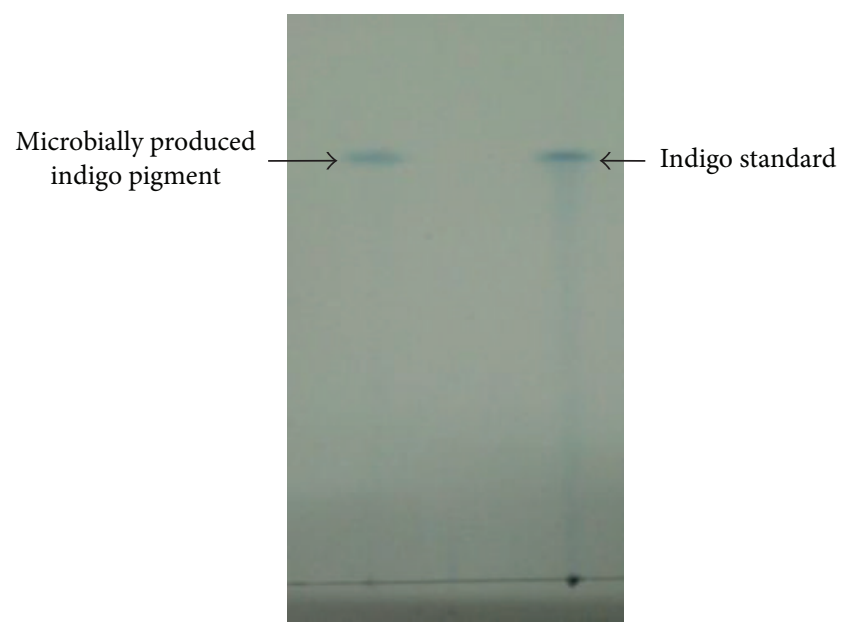

(a)

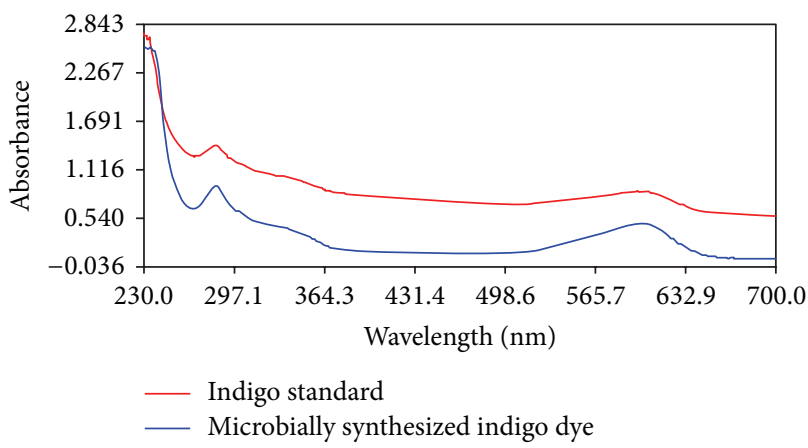

(b)

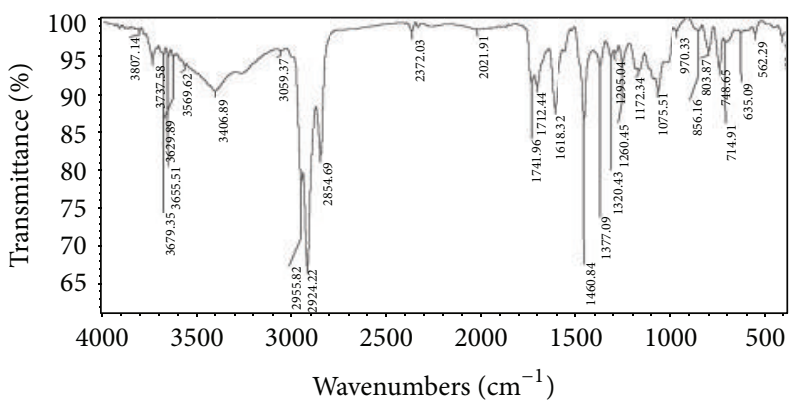

(c)

Figure 2: (a) TLC analysis of indigo pigment produced by Pseudomonas sp. HAV-1. (b) UV-Visible scan of indigo pigment produced by Pseudomonas sp. HAV-1. (c) FT-IR spectrum of indigo pigment produced by Pseudomonas sp. HAV-1.

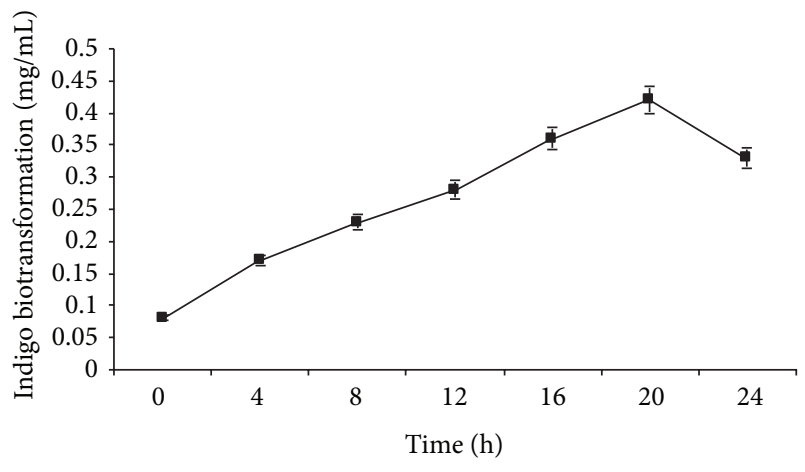

Figure 3: Induction profile of Pseudomonas sp. HAV-1 for indigo biotransformation using $3 \mathrm{mM}$ indole concentration at $30^{\circ} \mathrm{C}$ with initial $\mathrm{pH}$ of 7.0 .

3.5. Effect of Inoculum Size and Indole Concentration on Indigo Formation. Response surface method was used to understand individual as well as combined effect of inoculum size and indole concentration. From analysis of variance (ANOVA) (Table 1) it was established that neither inoculum size nor indole concentration was significant $(P$ values less than 0.05 indicate model terms are significant). Moreover, combined effect of these factors was not significant for indigo production. The contour plot in Figure 4 exhibits the behavior of indigo production with respect to changes in the initial inoculum size and indole concentration in the selected range. Indigo production was highest $\left(700 \mu \mathrm{g} \mathrm{mL}^{-1}\right)$ by increasing inoculum size to $14 \%$ with indole concentration of $7 \mathrm{mM}$. Furthermore, the indigo formation by Pseudomonas sp. HAV1 was superior when compared to other reported studies for indigo production (Table 2) [21, 22]. This implies that Pseudomonas sp. HAV-1 possesses tremendous potential as candidate for commercial production of indigo pigment.

3.6. Antioxidant Activity. The antioxidant activity of the microbially synthesized indigo pigment as determined by FRAP and ABTS assay was found to be comparable with the commercial indigo pigment (Table 3 ). To the best of our knowledge, this is the first report depicting the antioxidant activity of the microbially produced indigo pigment.

\section{Conclusion}

The strain Pseudomonas sp. HAV-1 exhibits exceptional potential for bioindigo production $\left(700 \mu \mathrm{g} \mathrm{mL}^{-1}\right)$ with 20 hours' induction time. Moreover, this study is the first account on exploration of antioxidant activity of bioindigo 


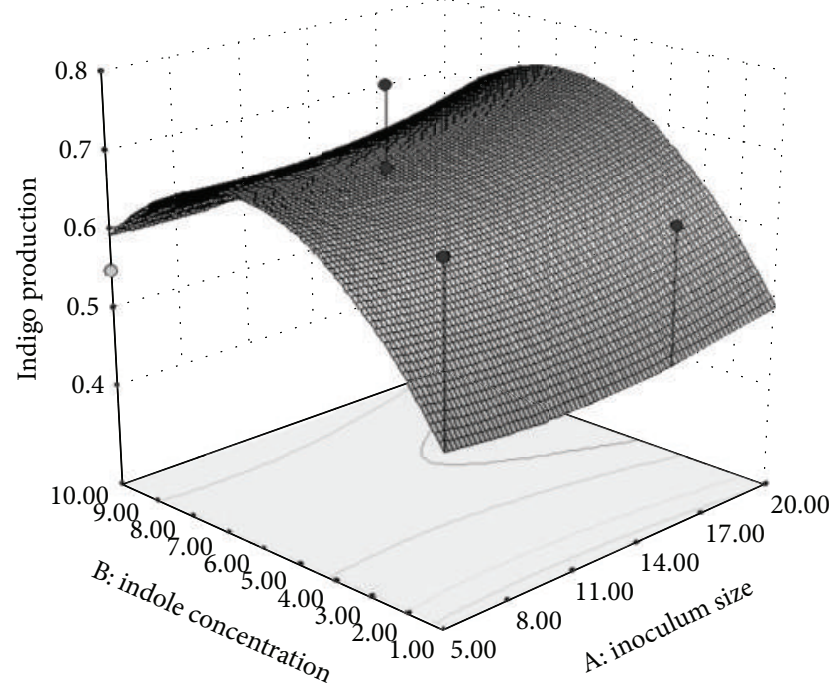

(a)

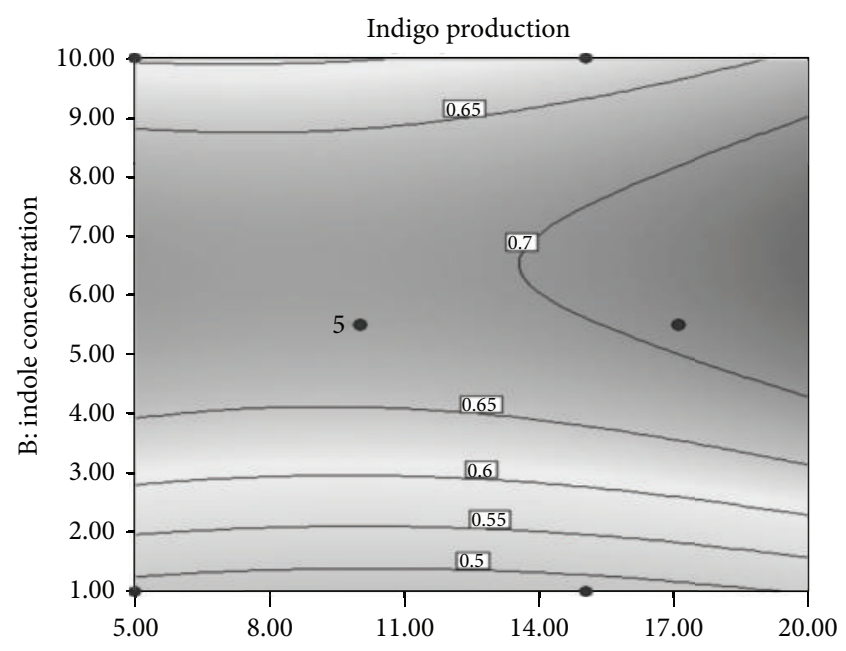

(b)

FIGURE 4: (a) 3D plot showing the interaction effect of indole concentration and inoculum size on indigo formation by Pseudomonas sp. HAV-1 and (b) Contour plot showing the interaction effect of indole concentration and inoculum size on indigo formation by Pseudomonas sp. HAV-1.

TABLE 2: Indigo production by different bacterial cultures.

\begin{tabular}{|c|c|c|c|}
\hline $\begin{array}{l}\text { Indigo } \\
\text { produced } \\
\left(\mu \mathrm{g} \mathrm{mL}^{-1}\right) \\
\end{array}$ & Time (h) & Culture & Reference \\
\hline $700^{*}$ & 24 & $\begin{array}{c}\text { Pseudomonas sp. } \\
\text { HAV-1 }\end{array}$ & Present study \\
\hline 292 & 24 & $\begin{array}{c}\text { Acinetobacter } \\
\text { ST-550 }\end{array}$ & [1] \\
\hline 662 & 24 & E. coli & {$[21]$} \\
\hline 246 & 8 & $\begin{array}{c}\text { Pseudomonas sp. } \\
\text { HOB1 }\end{array}$ & {$[4]$} \\
\hline 30 & 24 & Comamonas sp. & {$[22]$} \\
\hline
\end{tabular}

${ }^{*}$ After optimization.

TABLE 3: Antioxidant property of extracted indigo as well as commercial indigo.

\begin{tabular}{ccc}
\hline Assay & $\begin{array}{c}\text { Antioxidant property of } \\
\text { commercial indigo }\end{array}$ & $\begin{array}{c}\text { Antioxidant property of } \\
\text { indigo produced by } \\
\text { Pseudomonas sp. } \\
\text { HAV-1 }\end{array}$ \\
\hline FRAP & $0.13 \mathrm{mM} \mathrm{FeSO}_{4}$ equivalent & $0.50 \mathrm{mM} \mathrm{FeSO}_{4}$ equivalent \\
ABTS & $1 \mu \mathrm{M}$ ascorbic acid & $2.2 \mu \mathrm{M}$ ascorbic acid \\
equivalent & equivalent \\
\hline
\end{tabular}

pigment. The present study is, besides, a move towards green synthesis of indigo dye.

\section{Conflict of Interests}

The authors declare that there is no conflict of interests regarding the publication of this paper.

\section{Acknowledgment}

The authors are grateful to Gujarat Council on Science and Technology (GUJCOST), Gandhinagar, Gujarat, India, for providing the financial support.

\section{References}

[1] N. Doukyu, K. Toyoda, and R. Aono, "Indigo production by Escherichia coli carrying the phenol hydroxylase gene from Acinetobacter sp. strain ST-550 in a water-organic solvent twophase system," Applied Microbiology and Biotechnology, vol. 60, no. 6, pp. 720-725, 2003.

[2] Y. Gu, M. Lu, and W. J, "Process wastewater of indigotin production," Shanghai Chemical Industry, vol. 16, no. 1, pp. 12-14, 2001.

[3] Y. Qu, W. Pi, F. Ma, J. Zhou, and X. Zhang, "Influence and optimization of growth substrates on indigo formation by a novel isolate Acinetobacter sp. PP-2," Bioresource Technology, vol. 101, no. 12, pp. 4527-4532, 2010.

[4] H. Pathak and D. Madamwar, "Biosynthesis of indigo dye by newly isolated naphthalene-degrading strain Pseudomonas sp. HOB1 and its application in dyeing cotton fabric," Applied Biochemistry and Biotechnology, vol. 160, no. 6, pp. 1616-1626, 2010.

[5] B. D. Ensley, B. J. Ratzkin, T. D. Osslund, M. J. Simon, L. P. Wackett, and D. T. Gibson, "Expression of naphthalene oxidation genes in Escherichia coli results in the biosynthesis of indigo," Science, vol. 222, no. 4620, pp. 167-169, 1983.

[6] D. Murdock, B. D. Ensley, C. Serdar, and M. Thalen, "Construction of metabolic operons catalyzing the De novo biosynthesis of indigo in Escherichia coli," Nature Biotechnology, vol. 11, no. 3, pp. 381-386, 1993.

[7] Q. Ma, Y. Qu, X. Zhang, B. Xu, and J. Zhou, "Recent advances in microbial synthesis of indigo," Chinese Journal of Applied and Environmental Biology, vol. 18, no. 2, pp. 344-350, 2012. 
[8] X. Han, W. Wang, and X. Xiao, "Microbial biosynthesis and biotransformation of indigo and indigo-like pigments," Chinese Journal of Biotechnology, vol. 24, no. 6, pp. 921-926, 2008.

[9] G. J. Kapadia, H. Tokuda, R. Sridhar et al., "Cancer chemopreventive activity of synthetic colorants used in foods, pharmaceuticals and cosmetic preparations," Cancer Letters, vol. 129, no. 1, pp. 87-95, 1998.

[10] R. Hoessel, S. Leclerc, J. A. Endicott et al., "Indirubin, the active constituent of a Chinese antileukaemia medicine, inhibits cyclin-dependent kinases," Nature Cell Biology, vol. 1, no. 1, pp. 60-67, 1999.

[11] Z. Xiao, Y. Hao, B. Liu, and L. Qian, "Indirubin and meisoindigo in the treatment of chronic myelogenous leukemia in China," Leukemia \& Lymphoma, vol. 43, no. 9, pp. 1763-1768, 2002.

[12] S. Leclerc, M. Garnier, R. Hoessel et al., "Indirubins inhibit glycogen synthase kinase- $3 \beta$ and $\mathrm{CDK} 5 / \mathrm{P} 25$, two protein kinases involved in abnormal tau phosphorylation in Alzheimer's disease. A property common to most cyclindependent kinase inhibitors?" Journal of Biological Chemistry, vol. 276, no. 1, pp. 251-260, 2001.

[13] E. Farias-Silva, M. Cola, T. R. Calvo et al., "Antioxidant activity of indigo and its preventive effect against ethanol-induced DNA damage in rat gastric mucosa," Planta Medica, vol. 73, no. 12, pp. 1241-1246, 2007.

[14] F. M. Ausubel, R. Brent, R. E. Kingston, D. D. Moore, J. A. Seidman, and J. G. Smith, Current Protocols in Molecular Biology, unit 24, John Wiley and Sons, New York, NY, USA, 1997.

[15] H. Pathak, D. Kantharia, A. Malpani, and D. Madamwar, "Naphthalene degradation by Pseudomonas sp. HOB1: in vitro studies and assessment of naphthalene degradation efficiency in simulated microcosms," Journal of Hazardous Materials, vol. 166, no. 2-3, pp. 1466-1473, 2009.

[16] J. Felsenstein, "PHYLIP e phylogeny inference package (version 3.2)," Cladistics, vol. 5, no. 1, pp. 387-395, 1989.

[17] K. E. O'Connor and S. Hartmans, "Indigo formation by aromatic hydrocarbon-degrading bacteria," Biotechnology Letters, vol. 20, no. 3, pp. 219-223, 1998.

[18] K. Chauhan, U. Trivedi, and K. C. Patel, "Application of response surface methodology for optimization of lactic acid production using date juice," Journal of Microbiology and Biotechnology, vol. 16, no. 9, pp. 1017-1025, 2006.

[19] I. F. F. Benzie and J. J. Strain, "The ferric reducing ability of plasma (FRAP) as a measure of "antioxidant power": the FRAP assay," Analytical Biochemistry, vol. 239, no. 1, pp. 70-76, 1996.

[20] R. Re, N. Pellegrini, A. Proteggente, A. Pannala, M. Yang, and C. Rice-Evans, "Antioxidant activity applying an improved ABTS radical cation decolorization assay," Free Radical Biology \& Medicine, vol. 26, no. 9-10, pp. 1231-1237, 1999.

[21] G. H. Han, H.-J. Shin, and S. W. Kim, "Optimization of bioindigo production by recombinant $E$. coli harboring fmo gene," Enzyme and Microbial Technology, vol. 42, no. 7, pp. 617-623, 2008.

[22] Y. Qu, X. Zhang, Q. Ma et al., "Indigo biosynthesis by Comamonas sp. MQ," Biotechnology Letters, vol. 34, no. 2, pp. 353-357, 2012. 

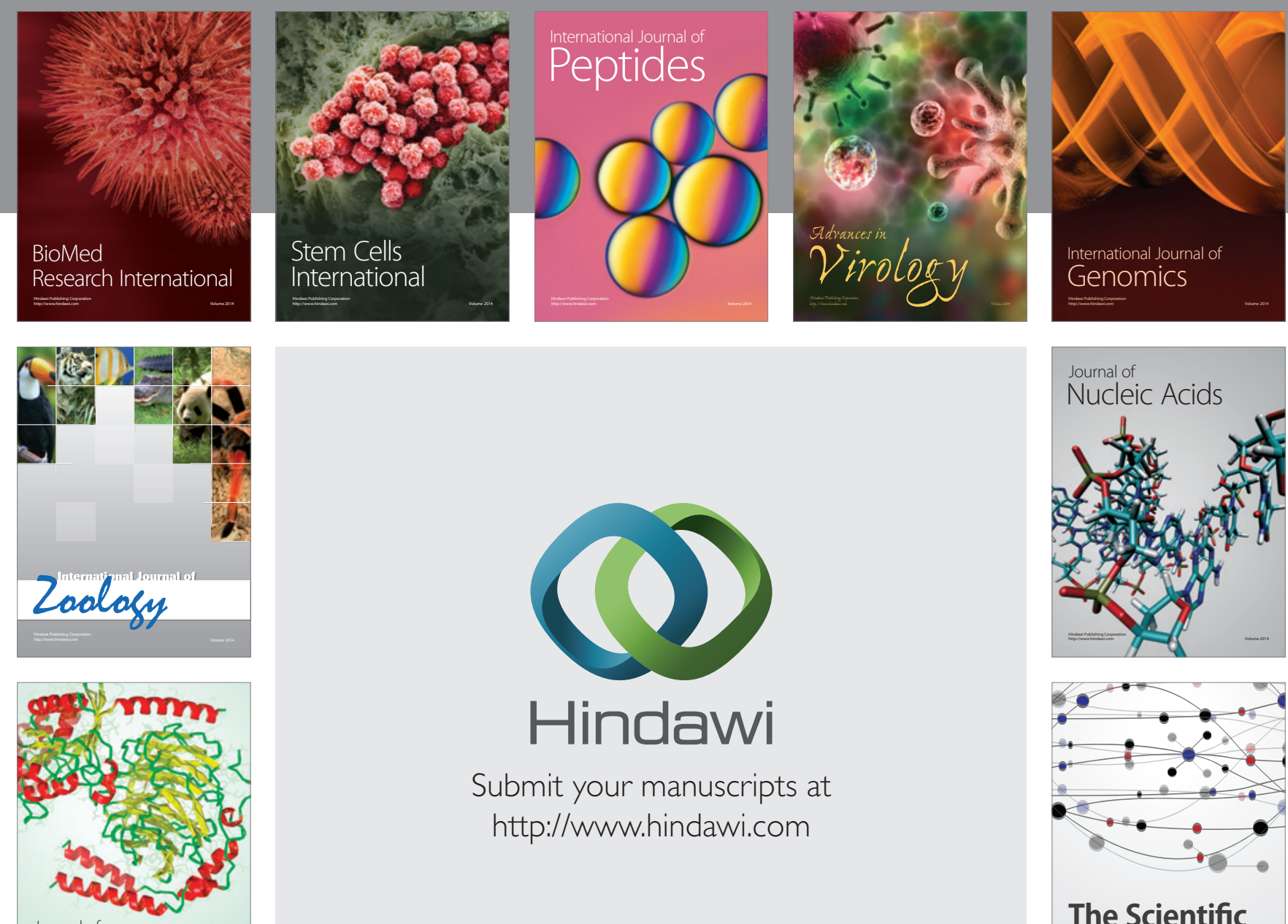

Submit your manuscripts at

http://www.hindawi.com

Journal of
Signal Transduction
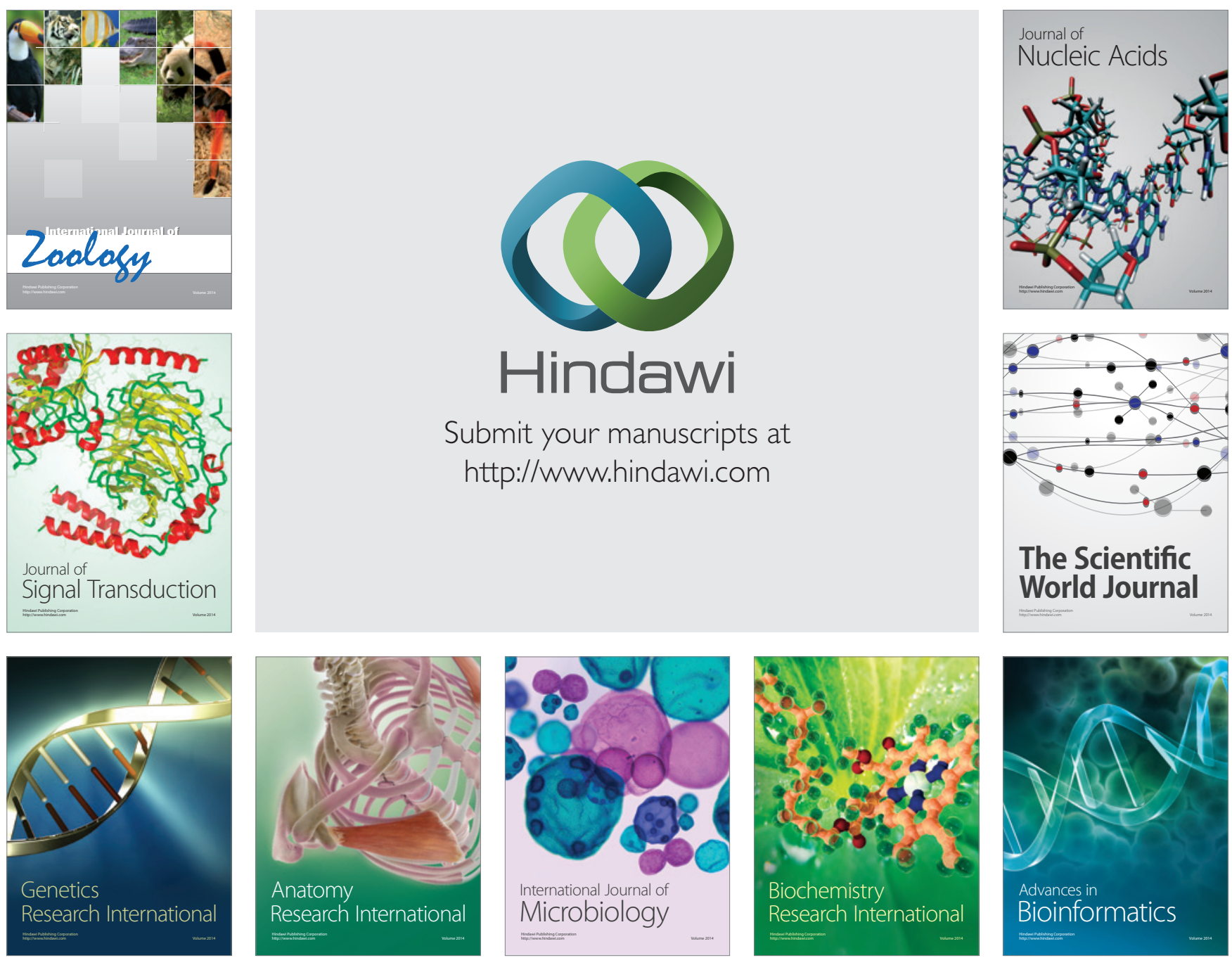

The Scientific World Journal
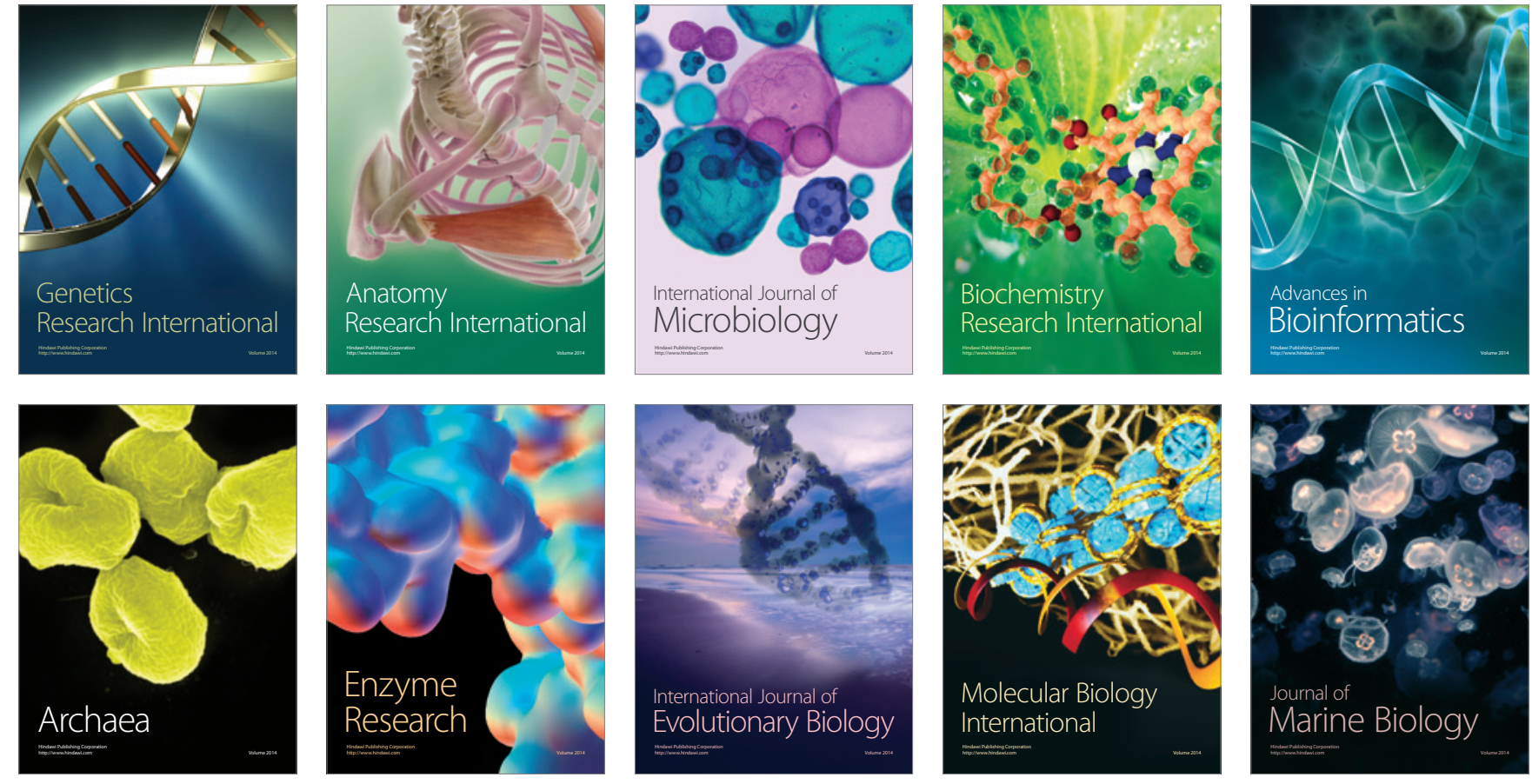